\title{
Bir Grup Tip Fakültesi Öğrencisinde Geleneksel ve Tamamlayıcı Tıp Tutumu ve Sağlık Okuryazarlığı İlişkisinin İncelenmesi
}

\author{
Examination of the Relationship between Traditional and Complementary Medicine
} Attitude and Health Literacy in a Group of Medical Faculty Students

\section{Elif Köse, Gökhan Oturak, Hasan Çetin Ekerbiçer}

Sakarya Üniversitesi Tip Fakültesi, Halk Sağlığı AD, Sakarya, Türkiye

\author{
Yazı̧sma Adresi / Correspondence: \\ Gökhan Oturak \\ Korucuk Mahallesi Konuralp Bulvarı No:81, 54290 Adapazarı/Sakarya \\ T: :+90 $5366481378 \quad$ E-mail: g.oturakmail.com \\ Geliş Tarihi / Received : 08.01.2021 Kabul Tarihi / Accepted : 27.03.2021 \\ Orcid: \\ Elif Köse https://orcid.org/0000-0002-2232-4538 \\ Gökhan Oturak https://orcid.org/0000-0003-1608-8433 \\ Hasan Çetin Ekerbiçer https://orcid.org/0000-0003-0064-3893 \\ ( Sakarya Tip Dergisi / Sakarya Med J 2021, 11(2):373-380 ) DOI: 10.31832/smj.856587
}

$\ddot{\mathrm{O} z}$

Amaç Son 30 yılda gelişmiş ve gelişmekte olan ülkelerde Geleneksel ve Tamamlayıcı Tip (GTT) kullanımında artış olmuştur. Türkiyẻde erişkin yaş grubunda yapılan bir çalışmada ise tamamlayıcı tıp uygulamalarını kullanma sıklığı $\% 60,5$ olarak bulunmuștur. Bu çalıșma ile tıp fakültesi öğrencilerinin GTT uygulamalarına olan tutumlarını ve sağlık okuryazarlı̆̆ (SOY) düzeylerini tespit etmek ve SOY ile GTT arasındaki ilişki incelenmek istenmiștir.

Gereç ve Tanımlayıcı tipteki bu araştırma 2019-2020 eğitim öğretim yılı içerisinde Sakarya Üniversitesi Tip Fakültesi Dönem I, II, III öğrencilerinde gerekli etik ve idari izinler

Yöntem alınarak yapılmıştır. Ankette sosyodemografik özellikler, kronik hastalık varlı̆ı̆, sigara ve alkol alışkanlı̆̆ı; GTT uygulamaları hakkında bilgi sahibi olma durumu, bilgi kaynağı, GTT uygulamalarını kullanma durumu ve nedenleri; GTT Tutum Ölçeği ve HÜSOY (Hacettepe Üniversitesi Sağlık Okuryazarlık Ölçeği kısa formu) ölçeği kullanılmıștır. Türkçe geçerlilik ve güvenirliği yapılmış GTT Tutum Ölçeği’nin Cronbach alfası 0,808; HÜSOY Ölçeğinin Cronbach alfası 0,84’tür.

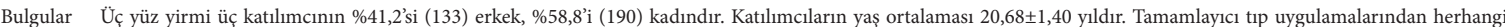
birini kullandığını ifade edenler katılımcıların \%8,7’si (28 kişi) olmuştur. Tamamlayıcı tıp uygulamaları hakkındaki bilgi kaynağının, katııımcıların \%60,7’si çevresi (aile, akraba), \%59,1'i internet, \%42,1'i televizyon, \%9,0'u sağlı personeli, \%5,9'u okul olduğunu ifade etmiştir. Katılımclların GTT tutum ölçeği ve HỨSOY ölçeğinden aldıkları ortalama puanlar sırasılla $104,72 \pm 16,46$ ve $21,75 \pm 2,23$ 'ır. Tamamlayıcı tıp tutum ölçeği ile sağlık okuryazarlığı ölçeği arasında anlamlı bir korelasyon saptanmamıștır $(\mathrm{r}=-0,044, \mathrm{p}=0,469)$

Öğrenciler arasında tamamlayıcı tıp uygulamaları hakkında bilgisi olduğunu düşünenlerin sayısı azdır. Ayrıca bu konuda güvenilir bilgi kaynaklarından bilgi almadıkları da anlaşılmaktadır. Tıp fakültesi öğrencilerinin bile tamamlayıcı tıp konusunda sağlıklı bilgiye ulaşmasında sorun olduğu göz önüne alındığında sağlık okuryazarlığının gerekliliği ve kapsamının önemi anlaşılmaktadır.

Anahtar Sağlık Okuryazarlığı; Geleneksel ve Tamamlayıcı Tıp; Tıp öğrencisi

Kelimeler

Abstract

Objective The use of Traditional and Complementary Medicine (TCM) has increased in developed and developing countries in the last 30 years. Frequency of use of complementary medicine practices in a study found $60.5 \%$ of the adult population in Turkey. With this study, it was aimed to determine the attitudes of medical faculty students towards complementary medicine practices and their health literacy levels and to examine the relationship between them.

Materials

This descriptive study was conducted in the 2019-2020 academic year by obtaining the necessary ethical and administrative permissions from Sakarya University Faculty of Medicine 1 st. 2 nd and 3rd year students. In the questionnaire; sociodemographic characteristics, presence of chronic diseases, smoking and alcohol habits, knowledge about TCM practices, source of information, usage status and reasons for use were questioned; The CACMAS (Complementary, Alternative and Conventional Medicine Attitude Scale) and HUSOY (Hacettepe University Health Literacy Scale short form) scale were used. The Cronbach alpha of the CACMAS is 0.808, the Cronbach alpha of the HUSOY Scale is 0.84, which have been validated and reliably in Turkish

Results Of the three hundred and twenty-three participants, $41.2 \%$ (133) were male, $58.8 \%(190)$ were female. The mean age of the participants is $20.68 \pm 1.40$ years. Those who stated that they used any of the complementary medicine practices were $8,7 \%$ (28 people) of the participants. The source of information on complementary medicine practices; $60.7 \%$ of the participants stated that they were around (family, relative), $59.1 \%$ were internet, $42.1 \%$ were television, $9.0 \%$ were health personnel, $5.9 \%$ were school. The mean scores the participants got from CACMAS and HÜSOY scales are $104.72 \pm 16.46$ and $21.75 \pm 2.23$, respectively. No significant correlation was found between the CACMAS and the HUSOY Scale $(r=-0.044, p=0.469)$.

Conclusion The number of students who think they know about complementary medicine practices is few. It is also understood that they do not receive information from reliable sources of information on this matter. Considering that even medical faculty students have a problem in accessing healthy information about complementary medicine, the necessity and importance of health literacy is understood.

Keywords Health Literacy; Traditional and Complementary Medicine; Medical student 


\section{GİRIŞ}

Dünya Sağlık Örgütü (DSÖ) geleneksel tıbbı fiziksel ve ruhsal rahatsızlıklardan korunma, tanı konması, iyileştirilmesi ve tedavisi için kullanılan; inanış, tecrübe ve teorilere dayanan bilgi, beceri ve uygulamalar olarak tanımlamaktadır. Geleneksel tıp, kültürden kültüre değişiklik gösterdiği için ülkelerin, hatta ülkeler içerisindeki bölgelerin farkl1, kendine özgü tedavi ve uygulamalarını kapsamaktadır. Bazı ülkelerde bu uygulamalar (CAM- Complementary Alternative Medicine) 'alternatif' ve 'tamamlayıcı' olarak adlandırılmaktadır. Gelişmiş ve gelişmekte olan ülkelerde son 30 yılda tamamlayıcı tıbbın kullanımında artış olmuştur. $^{1}$

Tamamlayıcı tıbbın destekleyici olması nedeniyle modern tıbbi uygulamalar kullanılırken, beraberinde hastanın rahatlaması, bağışıklığının güçlenmesi, psikolojik durumunun düzeltilmesi gibi amaçlarla da kullanılmaktadır.

Tip fakültesi öğrencilerinde yapılan çalışmalarda akupunktur uygulamasını bilme sıklığı \%59,5 ila \%89,9 arasında; kaplıca uygulamasını bilme sıklığı \%58,5 ila \%96,8 arasında, masaj uygulamasını bilme sıklığı \%66,6 ila \%96,0 arasında, dua uygulamasını bilme sıklığ $\% 73,1$ ila \%91,9 arasında, kupa uygulamasını bilme sıklığı \%75,3 ila \%92,1 arasında, bitkisel tedavi uygulamasını bilme sıklı̆̆ $\% 61,2$ ila \%94,3 arasindadır. $^{2-6}$

Tip fakültelerinde yapılan çalışmalarda en yüksek sıklıkla bilinen uygulamalar; kaplıca, masaj ve bitkisel tedavilerdir. Tip fakültesi öğrencilerinde yapılan çalısmalarda masaj uygulamasının kullanılma sıklığ $\% 15,4$ ila \%58,5 arasında, kaplıca uygulamasının kullanılma sıklığı \% 0,7 ila \%54,9 arasında, tamamlayıcı tıp uygulaması olarak dua edilme sıklığ $1 \% 5,4$ ila \%69,0 arasında, bitkisel tedavilerin kullanılma sıklığı \%10,4 ila \%51,3 arasındadır. Kupa uygulamasını kullanma sıklığ ise \%7,1'dir. ${ }^{3-5}$

Tip fakültesi müfredatında yer almayan GTT ile ilişkili konularda öğrenciler, bilgi kaynağı olarak çoğunlukla in- ternet ve sosyal medya kanallarını kullandıklarını belirtmektedirler. ${ }^{4,7-8}$

GTT (Geleneksel ve Tamamlayıcı Tip) konularına ilgisi olan öğrencilerin ders dışı kaynaklar ile bilgi ihtiyaçlarını karşıladıkları ve bilgilerini artırdıkları görülmektedir. Yapılan çalışmalarda tamamlayıcı tıp uygulamalarını \%47,7 ila \%76,9'unun çevresinden (aile, arkadaş, aktar), \%15,9 ila $\% 63,7$ 'sinin televizyon ya da internetten, \%4,1'inin kitap ve gazetelerden, $\% 8,4$ 'ünün bilimsel dergilerdeki yayınlardan, \%3,1 ila \%5,4'ünün sağllk personelinden bilgi edindiği görülmektedir. ${ }^{3,6,9,10}$

Öğrencilerin en fazla kullandığı GTT yöntemleri masaj $(\% 15,4)$, diyetler $(\% 10,4)$ ve fitoterapidir $(\% 10,4)$. Öğrenciler GTT yöntemlerinden akupresör, homeopati, osteopati ve reiki yöntemlerini hiç kullanmadıklarını ifade etmişlerdir. ${ }^{3}$

Türkiye'de erişkin yaş grubunda yapılan kapsamlı bir çalışmada ise tamamlayıcı tıp uygulamalarını kullanma sıklığı \%60,5 olarak bulunmuştur. Bu çalışma, kadınların bu uygulamalara daha çok başvurduğunu göstermekle birlikte, sosyoekonomik ve sosyokültürel açıdan farklı gruplarda uygulamaların kullanım sıklı̆̆ında fark gösterilememiştir. ${ }^{11}$

Türkiye'de geleneksel ve tamamlayıcı tıp uygulamalarına yönelik Ekim 2020 itibari ile Sağlık Bakanlığına bağlı; eğitim ve araştırma hastanelerinde 38 adet, üniversite hastanelerinde 26 adet hizmet veren uygulama merkezi bulunmaktadır. $^{12}$

Sağlık okuryazarlığı; kişilerin sağlığının korunması, geliştirilmesi ve iyileștirilmesi ile ilgili uygulamalara ait temel bilgilere ve hizmetlere ulaşabilme, yorumlayıp anlama olarak tanımlanabilir. ${ }^{13}$

Sağlık okuryazarlığı ile bireyler yaşamlarında doğru ve nitelikli sağlık kararları alabilmeleri için gerekli olan sağ- 
lık bilgilerini ve hizmetleri algılama, yorumlama ve analiz etme süreçlerinin bileşimi şeklinde tanımlanmaktadır. ${ }^{14}$

Sağlık Bakanlığının 2013-2017 Stratejik Planı hedeflerinden biri "Bireylerin kendi sağlı̆̆ nu arttırmak için sağlık okuryazarlığını geliştirmek” olarak belirlenmiştir. ${ }^{15}$

Sağlık çalışanları dışındaki internet, sosyal medya gibi bilgi kaynaklarının çoğunlukla kullanıldı̆̆ı GTT uygulamalarında sağlık okuryazarlığı daha da önem kazanmaktadır. İnternet ya da televizyon kanallarında ticari amaçlarla, bilimsel dayanak olmadan kişiler yanlış yönlendirilebilir. Bireylerin GTT yöntemleri hakkında bilgi sahibi olmak ve bilgilerin güvenilirliğini ayırt edebilmek için sağlık okuryazarlığı düzeyinin yüksek olması gerekmektedir. Araştırmalarımıza göre Türkçe literatürde tıp öğrencilerinde GTT uygulamaları ile sağlık okuryazarlığı ve sağlık algısı arasındaki ilişkiyi gösteren bir çalışma bulunmamaktadır.

$\mathrm{Bu}$ çalışma ile GTT uygulamalarının kolay ulaşılabilir olması ve kullanımının artmasından dolayı geleceğin hekimleri olan tıp öğrencilerinin tamamlayıcı tıp uygulamaları hakkında farkındalığını arttırmak amaçlanmıştır. ${ }^{16}$

Literatürde tıp fakültesi öğrencilerinde sağlık okuryazarlığı ya da GTT uygulamaları ile ilgili bilgi düzeyi ve tutumu araştıran çalışmalar vardır fakat tıp öğrencilerinde GTT uygulamaları ve sağlık okuryazarlığının irdelendiği bir çalışmaya rastlanmamıştır. Bu nedenle bu çalışma ile tıp fakültesinin ilk üç yılındaki öğrencilerde GTT ile ilgili tutumun sağlık okuryazarlığı ile ilişkisi incelenmiştir.

\section{GEREÇ ve YÖNTEMLER}

Tanımlayıcı tipteki bu araştırma 2019-2020 eğitim öğretim yılı içerisinde Sakarya Üniversitesi Tıp Fakültesi Dönem I, II, III öğrencilerinde yapılmıştır. Dönem I'deki 181 öğrencinin 126’sına $(\% 69,6)$, dönem II'deki 160 öğrencinin 69'una (\%43,1), dönem III’teki 144 öğrencinin 128'ine $(\% 88,9)$ ulaşılmıştır. Toplamda 485 kişiden oluşan evrenin \%66,6’sına (323 kişi) ulaşılmıştır. Öğrencilere tıp fakül- teinde teorik ders sonrası amfide anket formları dağıtılmıştır. Anket formlarının dağıtıldığı gün ve saatte derste olmayan öğrencilere ulaşılamamıştır. Bazı öğrenciler ise derste olsalar bile araştırmaya katılmayı kabul etmemişlerdir. Katılımcıların sözel onayı alınarak yüz yüze görüşme yöntemi ile doldurulan anket formları üç kısımdan oluşmaktadır. İlk kısım sosyodemografik özelliklerden (yaş, cinsiyet, sınıf, anne-baba eğitim durumu), kronik hastalık olma durumu, sigara, alkol alışkanlığı sorulmuştur. Ayrıca, 2014'te yayınlanan GTT Uygulamaları Yönetmeliğinde yer alan uygulamalar ile ilgili, bilgi sahibi olma durumu, bilgilerinin kaynağı, GTT uygulamalarını kullanma durumu, kullanma nedeni, gibi sorulardan oluşmaktadır. İkinci kısımda orijinalini 2010 yılında Mc Fadden ve arkadaşlarının geliştirdiği, Köse E ve arkadaşlarının Türkçe geçerlilik ve güvenirliğini yapmış olduğu 27 maddeden oluşmuş olup, 7’li likert şeklinde tasarlanmış GTT Tutum Ölçeği kullanılmıştır. Ölçeğin en başında yer alan skalada 1-7 puan skalası yer almakta, katılımcıdan her madde için l'den 7’ye kadar puan vermesi beklenmektedir. "1" "kesinlikle katılmıyorum”; “7” kesinlikle katıllyorum olarak belirtilmiştir. Ölçek maddelerinin 22'si pozitif (2, 3, 5, 6, 7, 10, 11, 12, 13, 14, 15, 16, 17, 18, 19, 20, 21, 22, 23, 24, 25, 27. maddeler), 5'i negatif $(1,4,8,9,26$. maddeler) ifadelerden oluşmaktadır. Negatif ifadelerden oluşan maddeler analiz edilirken ters şekilde (7-6-5-4-3-2-1) puanlanmaktadır. Ölçekte 1, 4, 8, 9 ve 26. önermeler ters puanlanmaktadır. Ölçeğin kesim değeri olmayıp alınan puan arttıkça kişiler GTT’ye karşı olumlu tutum sergilemektedirler.17 18-63 yaş arasındaki erişkinlerde yapılan geçerlilik güvenirlik çalışmasında alt boyut ve maddelerin dağılımı, "Tamamlayıcı Tibba Düşünsel Bakış" (18, 19, 21, 22, 24, 5, 7, 9. maddeler), "Modern Tibba Karşı Memnuniyetsizlik" (1, 4, 16, 14, 11,17, 26, 27, 20, 8. maddeler), "Sağlığa Bütüncül Bakış" (3, 10, 12, 13, 15, 23, 25, 2, 6. maddeler) şeklinde yapılanmaktadır. Tamamlayıcı tıp tutum ölçeğinin üç boyutu olduğu için iç tutarlılık belirleme aşamasında Cronbach Alfa Güvenirlik Katsayısı formülü kullanılmıştır. Ölçeğin bütün olarak Cronbach Alfa katsayısı 0,808'dir. ${ }^{18}$ 
Üçüncü kısmında iki alt boyuttan oluşan HÜSOY (Hacettepe Üniversitesi Sağlık Okuryazarlık Ölçeği kısa formu) ölçeği kullanılmıştır. Türkiye’ye özgü olarak geliştirilen ölçeğin kısa formu 24 maddenin yer aldığ 18 sorudan ve özyeterlilik bölümünden (16 madde/soru) oluşmaktadır. Ölçek tek boyut olarak değerlendirilir, ölçekten en az 0 , en fazla 24 puan alınmaktadır. HÜ-SOY kısa formunun Öz Yeterlilik bölümünden alınabilecek toplam puan en az 1, en fazla 48 puandır. Ölçeğin Cronbach alfa değeri $0.84{ }^{\prime}$ dür. ${ }^{19}$

Mevcut çalışmada HÜ-SOY kısa formunun tıp öğrencilerinde Cronbach alfası 0,700, Özyeterlilik ölçeğinin Cronbach alfası 0,806 olarak bulunmuştur. GTT tutum ölçeğinin Cronbach alfa düzeyi 0,706 olarak saptanmıştır.

Araştırma için Sakarya Üniversitesi Tip Fakültesi Girişimsel Olmayan Etik Kurulu'ndan (02.09.2019 tarih ve 242 sayılı) ve araştırmanın yürütüldüğü fakülte dekanından izin alınmıştır. Araştırmaya katılan bireylere gönüllü onam formu ile araştırma hakkında yeterli açıklama yapılarak, yazılı onamları alınmıştır. Ayrıca araştırmada kullanılacak olan ölçekleri geliştiren/Türkçeye uyarlanmasını sağlayan kişilerden mail yoluyla izin alınmıştır.

\section{İstatistiksel Analiz}

Çalışma kapsamındaki kategorik verilerde tanımlayıcı istatistikler sayı (n) ve yüzde (\%) şeklinde, sürekli değişkenler ise ortalama, standart sapma ve ortanca, çeyreklikler arası değişim olarak verilmiştir. Kategorik verilerin karşılaştırılmasında Ki-kare testi kullanılmıştır. Normal dağglım gösteren sürekli değişkenlerin iki grup arasındaki karşılaştırılmasında Student $\mathrm{t}$ testi, normal dağılmayan durumlarda Mann Whitney U test kullanılmıştır. Normal dağılan sürekli değişkenlerin ikiden fazla gruptaki durumunun karşılaştırılmasında ANOVA, normal olmayan durumlarda da Kruskal Wallis testi kullanılmıştır. Araştırma verilerinin değerlendirilmesinde SPSS 21.0 paket programı kullanılmıştır. Anlamlılık değeri $\mathrm{p}<0,05$ olarak kabul edilmiştir.

\section{BULGULAR}

Katılımcıların \%58,8'i kız öğrenciden oluşmaktadır. Katılımcıların \%17,3’ü (56 kişi) tamamlayıcı tıp uygulamaları hakkında bilgisi olduğunu ifade ederken, \%57,0'si (184 kişi) kararsız olduğunu, \%25,7’si (83 kişi) hiç fikrinin olmadığını belirtmiştir (Tablo 1).

\begin{tabular}{|c|c|}
\hline Değişkenler & n (\%) \\
\hline Yaş Ortalama $\pm S S$ & $20,68 \pm 1,40$ \\
\hline Ortanca (1.-3. Çeyrek) & $21(20-21)$ \\
\hline \multicolumn{2}{|l|}{ Cinsiyet } \\
\hline Erkek & $133(41,2)$ \\
\hline Kadın & $190(58,8)$ \\
\hline \multicolumn{2}{|l|}{ Yaşadığı yer } \\
\hline Yurtta & $199(62,0)$ \\
\hline Aile ile birlikte & $66(20,6)$ \\
\hline Evde arkadaşlarla & $36(11,2)$ \\
\hline Evde yalnız & $20(6,2)$ \\
\hline \multicolumn{2}{|l|}{ Anne eğitim düzeyi } \\
\hline Okur yazar değil & $12(3,7)$ \\
\hline Okur yazar & $7(2,2)$ \\
\hline İlkokul mezunu & $93(29,0)$ \\
\hline Ortaokul mezunu & $50(15,6)$ \\
\hline Lise mezunu & $83(25,9)$ \\
\hline Üniversite ve üzeri & $76(23,7)$ \\
\hline \multicolumn{2}{|l|}{ Baba eğitim düzeyi } \\
\hline Okur yazar değil & $2(0,6)$ \\
\hline Okur yazar & $2(0,6)$ \\
\hline İlkokul mezunu & $44(13,7)$ \\
\hline Ortaokul mezunu & $41(12,8)$ \\
\hline Lise mezunu & $81(25,2)$ \\
\hline Üniversite ve üzeri & $151(47,1)$ \\
\hline \multicolumn{2}{|l|}{ Sigara } \\
\hline İçiyor & $30(9,3)$ \\
\hline İçiyormuş, bırakmış & $18(5,6)$ \\
\hline Hiç içmemiş & $274(85,1)$ \\
\hline \multicolumn{2}{|l|}{ Kronik hastalık } \\
\hline Var & $34(10,7)$ \\
\hline Yok & $284(89,3)$ \\
\hline \multicolumn{2}{|c|}{ Tamamlayıcı tıp hakkında bilgi } \\
\hline Hiçbir fikri yok & $83(25,7)$ \\
\hline Kararsiz & $184(57,0)$ \\
\hline Bilgisi var & $56(17,3)$ \\
\hline
\end{tabular}


Cinsiyete ve eğitim dönemlerine göre GTT bilgileri arasında anlamlı bir fark saptanmamıştır (sırasıyla, $\mathrm{p}=0,239$; $\mathrm{p}=0,196)$ (tabloda gösterilmemiştir).

Tablo 2'deki uygulamalardan en az biri hakkında fikri olan 292 kişi $(\% 90,4)$, en az bir uygulamadan yararlanmış olan 28 kişi $(\% 8,8)$ vardır ve katılımcıların tamamı gelecekte en az bir uygulamadan yararlanmak istediğini ifade etmiştir. GTT uygulamalarından en az birinden yararlanmış olan 28 katılımcı arasında en son başvurulan yöntemler; \%46,4'ünde (13 kişi) kupa, \%21,4’ünde (6 kişi) fitoterapi, \%14,3'ünde (4 kişi) sülük uygulaması olmuştur. GTT uygulamalarına en sık başvurma nedenleri \%35,7'sinde (10 kişi) ağrı, \%10,7'sinde (3 kişi) psikolojik nedenler, \%7,1 'inde (2 kişi) saç dökülmesi, \%7,1’inde (2 kişi) soğuk alginlığ1 olmuştur.

Katılımcılara tamamlayıcı tıp uygulamalarını ileride tercih ederlerse neden tercih edecekleri sorulduğunda; \%45,8'i (148 kişi) tamamlayıcı olduğu, \%19,8’i (64 kişi) kolay ulaşıldığı, \%17’si (55 kişi) son çare olduğu, \%7,1’i (23 kişi) ucuz olduğu, \%6,8’i (22 kişi) güvenilir olduğu için şeklinde cevaplamışlardır. Katılımcıların \%3,5’i (11 kişi) ise bu soruya yanıt vermemiştir.

Tamamlayıcı tıp uygulamalarından herhangi birini kullanan 28 katılımcıya uygulamalardan fayda görüp görmedikleri sorulmuş 2 katılımcı soruya cevap vermemiştir. Cevap veren 26 katılımcıdan \%19,2'si (5 kişi) uygulamanın tamamen faydalı olduğunu, \%69,2'si (18 kişi) kısmen faydalı olduğunu, \%11,5’i (3 kişi) kararsız olduğunu belirtmiştir. Uygulanan tamamlayıcı tıp yöntemlerinden \%96,4'ünde (27 kişi) katılımcılar sorun yaşamadığını belirtmiş, bir kişi sorun yaşadığını belirtmiştir (tabloda gösterilmemiştir). Ayrıca, gelecekte kullanmayı düşündüğü uygulamaların sıklığı, halen ya da geçmişte kullanma sıklığına göre daha fazladır (Tablo 2).
Tablo 2. Geleneksel ve tamamlayıcı tıp uygulamaları hakkında fikir sahibi olma, kullanmış olma ya da kullanmak isteme durumlarının dağılımı

\begin{tabular}{|l|c|c|c|}
\hline $\begin{array}{l}\text { Tamamlayıcı } \\
\text { Uygulamaları }\end{array}$ & $\begin{array}{c}\text { Fikri olan } \\
\text { n }(\%)\end{array}$ & $\begin{array}{c}\text { Kullanmiş ya } \\
\text { da kullanıor } \\
\text { olmak } \\
\text { n }(\%)\end{array}$ & $\begin{array}{c}\text { Gelecekte } \\
\text { kullanmak } \\
\text { istediğiniz } \\
\text { n (\%) }\end{array}$ \\
\hline Akupunktur & $241(74,8)$ & $2(0,6)$ & $138(42,7)$ \\
\hline Apiterapi & $22(6,8)$ & - & $10(3,1)$ \\
\hline Fitoterapi & $94(29,2)$ & $5(1,5)$ & $56(17,3)$ \\
\hline Sülük & $268(83,2)$ & $9(2,8)$ & $73(22,6)$ \\
\hline Hipnoz & $221(68,8)$ & $2(0,6)$ & $103(31,9)$ \\
\hline Homeopaati & $12(3,7)$ & - & $8(2,5)$ \\
\hline Kayropraktik & $18(5,6)$ & - & $12(3,7)$ \\
\hline Kupa & $191(59,5)$ & $15(4,6)$ & $68(21,1)$ \\
\hline Larva & $28(8,8)$ & - & $4(1,2)$ \\
\hline Mezoterapi & $17(5,3)$ & $1(0,3)$ & $13(4,0)$ \\
\hline Proloterapi & $2(0,6)$ & - & $3(0,9)$ \\
\hline Osteopati & $17(5,3)$ & - & $14(4,3)$ \\
\hline Ozon & $62(19,4)$ & - & $33(10,2)$ \\
\hline Refleskoloji & $30(9,4)$ & - & $25(7,7)$ \\
\hline Müzik terapi & $176(55,0)$ & $2(0,6)$ & $141(43,7)$ \\
\hline
\end{tabular}

GTT ile ilgili edinilen bilgi kaynaklarından \%60,7 ile ilk s1rada çevre (aile ve akrabalar) yer almakta, internet $(\% 59,1)$ ve televizyon $(\% 42,1)$ takip etmektedir (Tablo 3).

Tablo 3. Katılımcıların geleneksel ve tamamlayıcı tıp ile ilgili bilgileri edindiği kaynakların dağılımı

\begin{tabular}{|l|c|}
\hline Kaynak & $\mathrm{n}(\%)$ \\
\hline Çevre (aile, akraba) & $196(60,7)$ \\
\hline İnternetten & $191(59,1)$ \\
\hline Televizyondan & $136(42,1)$ \\
\hline Arkadaşından & $56(17,3)$ \\
\hline Kitaplardan & $55(17,0)$ \\
\hline Dergi ve gazetelerden & $53(16,4)$ \\
\hline Sağlık personelinden & $29(9,0)$ \\
\hline Okuldan & $19(5,9)$ \\
\hline
\end{tabular}

Katılımcıların GTT tutum ölçeği, HÜ-SOY ölçeği ve öz yeterlilik ölçeğinden aldıkları puanların ortalaması sırasıyla 104,72, 21,75 ve 40,23’tür. Ölçeklerden alınan puanlarla ilgili ayrıntılı tanımlayıcı istatistikler tablo 4'te gösterilmiştir. 
Tablo 4. Geleneksel ve Tamamlayıcı Tip Tutum Ölçeği ve HÜ-SOY ölçekleri ve Alt Boyutlarından elde edilen puanların dağılımı

\begin{tabular}{|l|c|c|}
\hline Ölçekler & $\begin{array}{c}\text { Ort. } \pm \text { Stand. } \\
\text { Sapma }\end{array}$ & $\begin{array}{c}\text { Ortanca } \\
\text { (ÇADA) }\end{array}$ \\
\hline Tamamlayıcı Tıp Tutum Ölçeği & $104,72 \pm 16,46$ & $104(93-117)$ \\
\hline $\begin{array}{c}\text { Tamamlayıcı tıbba düşünsel } \\
\text { bakış }\end{array}$ & $26,93 \pm 8,01$ & $27(22-33)$ \\
\hline $\begin{array}{l}\text { Modern tıbba karşı memn- } \\
\text { uniyetsizlik }\end{array}$ & $36,62 \pm 6,37$ & $36(32-40)$ \\
\hline Sağlığa bütüncül bakış & $45,08 \pm 7,37$ & $45(40-50)$ \\
\hline Sağlık Okuryazarlığı Kısa Form & $21,75 \pm 2,23$ & $22(21-23)$ \\
\hline Öz yeterlilik Ölçeği & $40,23 \pm 4,53$ & $41(37-44)$ \\
\hline \multicolumn{2}{|l|}{ ÇADA= Çeyrekler Arası Dağılım Aralığ1 } \\
\hline
\end{tabular}

Erkek öğrencilerde GTT ölçeğinden ve GTT Ölçeğinin Tamamlayıcı tıbba düşünsel bakış alt boyutundan alınan puanlar kız öğrencilerden yüksek olarak saptanmıştır. İstatistiksel olarak da anlamlıdır (Tablo 5).

\begin{tabular}{|l|c|c|c|}
\hline \multicolumn{4}{|c|}{ Tablo 5. Cinsiyete göre Geleneksel ve Tamamlayıcı Tip Tutum } \\
Ölçeği ve Sağlık Okuryazarlığı Ölçeklerinin Dağlımı \\
\hline Ölçekler ve alt boyutları & Erkek & Kadın & $\mathrm{p}$ \\
\hline $\begin{array}{l}\text { Tamamlayııı Tıp Tutum } \\
\text { Ölçeği Ortanca (1.-3. Çeyrek) }\end{array}$ & $\begin{array}{c}105 \\
(97-120)\end{array}$ & $\begin{array}{c}102 \\
(91-111)\end{array}$ & 0,010 \\
\hline $\begin{array}{l}\text { Tamamlayıcı tıbba düşünsel } \\
\text { bakış (OrtıSS) }\end{array}$ & $28,14 \pm 8,32$ & $26,03 \pm 7,68$ & 0,025 \\
\hline $\begin{array}{l}\text { Modern tıbba karşı } \\
\text { memnuniyetsizlik Ortanca } \\
\text { (1.-3. Çeyrek) }\end{array}$ & $\begin{array}{c}36 \\
(33-41,5)\end{array}$ & $\begin{array}{c}36 \\
(32-40)\end{array}$ & 0,251 \\
\hline $\begin{array}{l}\text { Sağlığa bütüncül bakıș } \\
\text { Ortanca (1.-3. Çeyrek) }\end{array}$ & $\begin{array}{c}45 \\
(39-50)\end{array}$ & $\begin{array}{c}46 \\
(40,5-50,5)\end{array}$ & 0,404 \\
\hline $\begin{array}{l}\text { Sağlık Okuryazarlığı Kısa } \\
\text { Form Ortanca (1.-3. Çeyrek) }\end{array}$ & $\begin{array}{c}22 \\
(21-23)\end{array}$ & $\begin{array}{c}22 \\
(21-23)\end{array}$ & 0,148 \\
\hline $\begin{array}{l}\text { Öz yeterlilik Ölçeği } \\
\text { Ortanca (1.-3. Çeyrek) }\end{array}$ & $\begin{array}{c}40 \\
(36-43)\end{array}$ & $\begin{array}{c}41 \\
(39-44)\end{array}$ & 0,072 \\
\hline
\end{tabular}

Kronik hastalığın varlığına göre ölçeklerden alınan puanların ortalamaları arasında fark saptanmamıştır (GTT Tutum Ölçeği p=0,524; Tamamlayıcı tıbba düşünsel bakış $\mathrm{p}=0,984$; Modern tıbba karşı memnuniyetsizlik $\mathrm{p}=0,091$; Sağlığa bütüncül bakış p=0,785; Sağlık Okuryazarlığı Kısa Form p=0,361; Öz yeterlilik Ölçeği p=0,699).

Tamamlayıcı tıp tutum ölçeği ile SOY ölçeği arasında ya da öz yeterlilik boyutu arasında anlamlı bir korelasyon saptanmamıştır (sırasıyla, $r=-0,044, p=0,469 ; r=-0,035$, p=0,567). Tamamlayıcı Tip Tutum ölçeği ile ölçeğin alt boyutları arasında istatistiksel olarak anlamlı ilişkiler saptanmıştır. Tamamlayıcı tıp tutum ölçeği ile Tamamlayıcı tıbba düşünsel bakış arasında pozitif yönde kuvvetli $(r=0,750$, $\mathrm{p}<0,001)$; Modern tıbba karşı memnuniyetsizlik ile arasında pozitif yönde orta düzeyde $(r=0,452, \mathrm{p}<0,001)$; Sağlığa bütüncül bakış ile arasında da pozitif yönde orta düzeyde bir ilişki $(r=0,498, p<0,001)$ saptanmıştır. HÜ-SOY kısa form ile alt boyutu olan Öz yeterlilik arasında da pozitif yönde zayıf bir ilişki saptanmıştır $(r=0,225, p<0,001)$. Öz yeterlilik alt boyutu ile Sağlığa bütüncül bakış alt boyutu arasında da pozitif yönde çok zayıf bir ilişki saptanmıştır $(\mathrm{r}=0,129, \mathrm{p}=0,028)$.

\section{TARTIŞMA}

Bu çalışmada GTT tutumu ile Sağlık Okuryazarlığı arasındaki ilişki incelenmiştir. Genel olarak güçlü bir ilişki bu araştırmanın verileri ile saptanmamakla birlikte literatürde istatistiksel olarak anlamlı ilişkiler olduğunu gösteren çalışmalar vardır. Dursun ve arkadaşlarının çalışmasında sağlık okuryazarlığı ile GTT uygulamaları arasında negatif yönlü zayıf düzeyde ilişki bulunmuştur. Sağlık okuryazarlığı puanı arttıkça geleneksel ve tamamlayıcı tıp tutumu ölçeğinden alınan puan azalmaktadır.20 Aksine sağlık okuryazarlığı arttıkça GTT uygulamalarının arttığını gösteren çalışmalar da mevcuttur. Bu farklılıklar kültürel nedenler ve yaşa bağlı bir değişim olabilir. ${ }^{21,22}$

Tamamlayıcı tıp uygulamalarından fikir sahibi oldukları uygulamalardan ilk beşi \%83,2 ile Sülük, \%74,8 sıklıkla Akupunktur, \%68,8 ile hipnoz, \%59,5 ile kupa uygulamas1, \%55 ile müzik terapi gelmektedir. Üniversite öğrencilerinde yapılan bir çalışmada da benzer sıklıkta, en çok bilinen ilk 5 uygulamanın sırasıyla kupa uygulaması 206 kişi (\%78.0), sülük uygulaması 198 kişi (\%75), hipnoz 193 kişi $(\% 73,1)$ ile müzik terapi 166 kişi $(\% 62,8)$, akupunktur 143 kişi $(\%$ 54,2) olduğu belirlenmiştir.23 AFSÜ Tip Fakültesi öğrencilerinin GTT yöntemlerini bilme ve kullan- 
ma durumları incelendiğinde $\% 92,1$ sıklıkta kupa tedavisi bulunmaktadır. ${ }^{5}$

Aile sağlığı merkezine başvuran 18-65 yaş arası 214 hasta üzerinde Dursun ve arkadaşlarının yaptığ 1 çalışmada, katılımcıların GTT tutum ölçeğinden aldıkları puanların ortalaması 103,99'dur. Bizim çalışmamızda da ölçek ortalama puanı benzer şekilde 104,72 'dir. $^{20}$

Mevcut çalışmada da literatürdekine benzer şekilde kadın öğrencilerin GTT tutum ölçeği puanları erkek öğrencilerin GTT tutum ölçeği puanına göre anlamlı olarak yüksek bulunmuştur. ${ }^{18}$ Bu durum kadınların çevresinde GTT uygulamalarını kullananların sıklığının erkeklere göre daha fazla olmasından kaynaklanıyor olabilir.

Çalışmada genel olarak ankette sorulan tamamlayıcı tıp uygulamalarını kullanmadıklarını belirtmişlerdir. Ancak, gelecekte tamamlayıcı tıp uygulamalarını kullanmayı düşünenlerin sıklığı geçmişte kullananlara göre çok daha yüksektir.

Katılımcıların \%60,7'si uygulamalarla ilgili bilgileri çevrelerinden, \%59,1'i internetten, \%42,1'i televizyondan, $\% 17,3$ ü arkadaşından, sadece \%9'u sağlık personelinden, \%5,9’u okuldan öğrendiğini belirtmiştir. Benzer şekilde 2019'da üniversite öğrencilerinde yapılan bir çalışmada da TAT yöntemleri konusundaki bilgiyi internet $(\% 55,9)$, arkadaş $(\% 33,5)$, sağlık personeli $(\% 18,2)$ ve akraba/komşu $(\% 12,4)$ aracılığıyla öğrendikleri tespit edilmiştir (Tablo 1). ${ }^{10}$ Başka bir araştırmada da benzer şekilde bilgi kaynağ olarak sıklıkla $(\% 25,4)$ internet, gazete, dergi, televizyon, medyayı tercih ederlerken, sadece $\% 8,4$ 'ü bilimsel dergilerdeki yayınlardan yararlanmakta ve \%5,4’ü diğer sağlık ekip üyelerinden bilgi almaktadırlar. ${ }^{3}$ Taşpınar ve arkadaşlarının çalışmasında da bilgi edinme kaynaklarının önemli kısmının çevre (\%49) ve internet (\%29) olduğu saptanmıştır. $^{24}$

\section{SONUÇ}

Öğrenciler arasında tamamlayıcı tıp uygulamaları hakkında bilgisi olduğunu düşünenlerin sayısı azdır. Ayrıca bu konuda güvenilir bilgi kaynaklarından bilgi almadıkları da anlaşılmaktadır. Tıp fakültesi öğrencilerinin bile tamamlayıcı tıp konusunda sağlıklı bilgiye ulaşmasında sorun olduğu göz önüne alındığında sağlık okuryazarlığının gerekliliği anlaşılmaktadır.

Etik Kurul Onayı: Araştırma için Sakarya Üniversitesi Tıp Fakültesi Girişimsel Olmayan Etik Kurulu'ndan (02.09.2019 tarih ve 242 sayılı) ve araștırmanın yürütüldüğü fakülte dekanından izin alınmıștır. 


\section{Kaynaklar}

1. WHO, Traditional medicine, http://www.who.int/topics/traditional_medicine/en/ (Erișim tarihi: 27 Teтmиz 2016)

2. Ergin A, Hatipoğlu C, Bozkurt Aİ, Mirza E, Kunak D, Karan C, Özçelik G, Teğin C, Pazır Y, Ptrtı İ, Uzmanlık ve tıp ögrencilerinin tamamlayıct-alternatif tıp hakkındaki bilgi düzeyleri ve tutumlari, Pam Med J 2011;4(3):136-143

3. Basatemür M, Güneş G, Aylaz R. Tip Fakültesi Öğrencilerinin Geleneksel ve Tamamlayıcı Tedavi Konusunda Bilgi, Tutum ve Davranışları. ESTÜDAM Halk Sağhlğı Dergisi. 2020;5(1):43-52.

4. Sönmez CI, Bașer DA, Küçükdağ HN, Kayar O, Acar İ, Güner PD, Tip Fakültesi Öğrencilerinin Geleneksel ve Tamamlayıcı Tip ile İlgili Bilgi Durumlarının ve Davranışlarının Değerlendirilmesi, Konuralp Tip Dergisi 2018;10(3): 276-281

5. Şenol Y, Erdemli B, Demirezen B. Tip fakültesi öğrencilerinin geleneksel ve tamamlayıcı tip hakkındaki bilgi ve davranıșlarının incelenmesi. Anadolu Güncel Tip Derg 2020; 2(1): 6-12.

6. Altan S, Rahman S, Çam S, Tip Fakültesi Öğrencilerinin Tamamlayıcı ve Alternatif Tip Yöntemleri ile İlgili Bilgi ve Tutumlar, Turkiye Klinikleri J Med Ethics 2014;22(3)

7. Yurtseven E, Vehid S, Bosat M, et al. Assessment of knowledge and attitudes toward Complementary and Alternative Medicine (CAM) amongst Turkish medical faculty students. African Journal of Traditional, Complementary Alternative Med 2015; 12: 8-13.

8. Samara AM, Barabra ER, Quzaih HN, et al. Use and acceptance of complementary and alternative medicine among medical students: A cross sectional study from Palestine. BMC Complementary Alternative Med 2019; 19: 78.

9. Șensoy N, Özdinç̧̧, Yilmaz O, Çetin MD, Tola D, Doğantekin P, Kurt G, Erden B, Üniversite Hastanesine Başvuran Hastaların Tamamlayıı Ve Alternatif Tedavi Kullanımına Yönelik Tutum Ve Davranışları, Kocatepe Tip Dergisi, 21:258-263/ Temmuz/ 2020

10. Solmaz T, Altay B. The status of college students about using complementary and alternative treatment methods. Pam Med J 2019;12:387-393.

11. Şimşek B., Yazgan-Aksoy D., Calik-Basaran N., Taş D., Albasan D. ve Kalaycı M. Z. (2017) Mapping Traditional and Medicine in Turkey. European Journal of Integrative Medicine 15: 68-72.

12. Sağllk Bakanlı̆ına Bağll Uygulama Merkezleri, https://shgmgetatdb.saglik.gov.tr/TR21482/saglik-bakanligina-bagli-uygulama-merkezleri.html (Erișim Tarihi: 15.10.2020)

13. Peerson A. and Saunders M. (2009). Health Literacy Revisited: What Do We Mean and
Why Does it Matter? Health Promotion International 2009; 24(3): 285-296.

14. Özcan V, Altunpolat R, Sağllk okuryazarlı̆̆ı ve sağllk okuryazarlı̆̆ında eczacının rolü. TEB Haberler (2013):15-21.

15. T.C. Sağllk Bakanlı̆̆ Strateji Planı 2013-2017, https://shgm.saglik.gov.tr/Eklenti/9843/0/ saglik-bakaligi-stratejik-plan--2013-2017pdf.pdf (Erişsim Tarihi: 02.11.2020)

16. Ilgaz A, Gözüm S, Tamamlayıcı sağlık yaklașımlarının güvenilir kullanımı için sağ̆lk okur yazarlğının önemi. Dokuz Eylül Üniversitesi Hemșirelik Fakültesi Elektronik Dergisi 2016; 9(2): 67-77.

17. McFadden KL, Hernández TD, and Ito TA, Attitudes Towards Complementary and Alternative Medicine Influence Its use. Explore, 2010; 6(6):380-388

18. Köse E, Ekerbiçer HC, Erkorkmaz Ü, Complementary, Alternative and Conventional Medicine Attitude Scale: Turkish Validity Reliability Study, Sakarya Tip Dergisi, 2018;8(4):726736.

19. Özvarış ŞB, Doğan BG, Çaman ÖK, Ŭnlü HK, Doğan N, Gelbal S, Sakarya S, Hacettepe Üniversitesi Sağlık Okuryazarlğ̆ Ölçeği,(HÜ-SOY), Hacettepe Üniversitesi Halk Sağlğ̆l Enstitüsü, 2018, Ankara, ISBN_978-605-83315-4-9.

20. Dursun Sİ, Vural B, Keskin B, Kaçar HK, Beyhan A, Kadıoğlu H, Yetişkinlerde Geleneksel/ Tamamlayıcı Tip Tutumu ile Sağlık Okuryazarlığı ve Sağlı Algısı Arasındaki İlișki, HALK SAĞLIĞI HEMȘIRELİĞİ DERGİSİ, 2019 - 1(1)

21. Owen-Smith A, McCarty F, Hankerson-Dyson D, DiClemente R, Prevalence and predictors of complementary and alternative medicine use in African-Americans with acquired immune deficiency syndrome. Focus on alternative and complementary therapies, 2012; 17(1): 33-42. https://doi.org/10.1111/j.2042-7166.2011.01140.x

22. Bains S, Egede LE, Association of health literacy with complementary and alternative medicine use: a cross-sectional study in adult primary care patients. BMC complementary and alternative medicine, 2011; 11(1): 138. https://doi.org/10.1186/1472-6882-11-138

23. İlhan AO, Sirekbasan S, Gürkök T, Sağlk Hizmetleri Meslek Yüksek Okulu Öğrencilerinin Geleneksel ve Tamamlayıcı Tip ile İlgili Bilgi Düzey ve Tutumlarının Değerlendirilmesi, Ankara Med J, 2019;(4):736-44, DOI: 10.17098/amj.651980.

24. Tasspınar B, Tasspınar F, Gökçen S, Erdoğan A, Okur İ, Okur E, Sağlık bilimleri öğrencilerinin tamamlayicı ve alternatif tedavilerle ilgili bilgi, tutum ve inanıșlarının araștırılması, $J$ Exerc Ther Rehabil. 2020;7(2):128-136 